\title{
O PAPEL DA EDUCAÇÃO PATRIMONIAL NO DIÁLOGO COM OS AGENTES SOCIAIS DO CONSELHO MUNICIPAL DE COMBATE Ȧ DISCRIMINAÇÃO E AO RACISMO (COMCEDIR) DE ARARAQUARA: REPENSANDO REPRESENTAÇÕES SOCIAIS NOS ESPAÇOS
MUSEAIS DE ARARAQUARA-SP.
}

\section{Robson Rodriques}

Doutor em Arqueologia pelo MAE/USP. Pós-doutorando PNPD-Capes do PPGCS-INCIS-UFU. Pesquisador-colaborador da Fundação Araporã. robson_arqueo@yahoo.com.br

\section{Dulcelaine Lopes Nishikawa}

Mestre em Engenharia Ambiental pelo CRHEA/USP e Doutora em Sociologia pela FCL/Unesp. Coordenadora do Grupo de Educação Ambiental da Fundação Araporã. dulcenishi@yahoo.com.br

\section{Talita Mara Catini}

Graduada em Ciências Sociais pela FCL/Unesp. Membro GEP - Fundação Araporã. talitacatini@gmail.com

\section{Ana Patrícia Ferreira da Silva}

Graduada em Ciências Sociais pela FCL/Unesp. Membro GEP - Fundação Araporã. anacajueiro@gmail.com

\begin{abstract}
reSUmO: Resultado de um projeto maior, intitulado "Recuperação e Conservação de Acervos do Patrimônio Histórico e Cultural de Araraquara", a proposta de trabalho promoveu ações de curadoria e conservação com curso de capacitação técnica de agentes dos Museus de Araraquara além de um programa de Educação Patrimonial. As ações educativas foram desenvolvidas com alunos de uma escola pública e com os representantes do Conselho Municipal de Combate à Discriminação e ao Racismo (COMCEDIR). O trabalho permitiu um diálogo, entre educadores e agentes sociais, a respeito das possíveis formas de se observar o passado, tendo em vista as possibilidades para se preservar e promover a sustentabilidade do patrimônio cultural, local e regional. 0 diálogo foi estabelecido, a partir de estímulos da imaginação do público acerca de outros períodos históricos e a respeito de outras formas de se pensar os patrimônios existentes nos espaços museais. A metodologia utilizada foi colocar o público no centro da ação pedagógica, utilizando o patrimônio arqueológico e histórico-cultural musealizado do município.
\end{abstract}

Palauras-chave: Identidade, Diversidade, Educação Patrimonial, Movimentos Sociais. abstract: Outcome from a bigger Project, titled "Recovery and Conservation of Collections of the Historical and Cultural Patrimony of Araraquara", the work proposal promoted curatorial and conservation actions with a technical training course for agents of the Araraquara Museums as well as a o Patrimonial Education program. The educative actions were developed with students from public schools and representatives of the Municipal Council to Combat Discrimination and Racism (COMCEDIR). The work allowed a dialog, between educator and social agent, regarding possible ways of looking at the past, in view of the possibilities to preserve and promote patrimonial culture sustainability, local and regional. The dialogue was established from public imagination stimuli about other historical periods and concerning other ways to think about the patrimonial existence on museums spaces. The methodology used was to make the public the center of the pedagogical action, using archeological and historicalcultural patrimony musealized of the city.

Key-words: Identity, Diversity, Patrimonial Education, Social Moviments. 


\section{introdução}

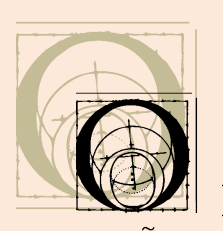

presente trabalho é fruto de um projeto maior intitulado "Recuperação e Conservação de Acervos do Patrimônio Histórico e Cultural de Araraquara". O projeto foi fírmado mediante convênio entre a Fundação Araporã e a Secretaria da Cultura do Estado de São Paulo. Entre os objetivos definidos no plano de ação do projeto, o de maior relevância foi o desenvolvimento de um Programa de Recuperação e Conservação do Patrimônio Histórico e Cultural de acervos existentes nos espaços museais do município de Araraquara, visando a manutenção dos conjuntos de peças e documentos existentes nos museus. Para atingir os objetivos do programa, direcionamos as ações para a educação patrimonial, oferecendo formação e qualificação profissional com conhecimentos apropriados nas temáticas de conservação preventiva e restauro de acervos musealizados.

A nossa busca era pela formação de uma identidade com os patrimônios existentes e a promoção da sua manutenção. Assim, passamos a apresentar o patrimônio cultural do município de maneira incisiva, sempre na busca de difundir informações a respeito da importância de tais acervos junto à população local, contribuindo para a sua preservação e valorização cultural.

No desenvolvimento das ações propostas no plano da conservação preventiva foram destaques a recuperação das coleções salvaguardadas pelo Museu de Arqueologia e Paleontologia de Araraquara (MAPA), pelo Museu Histórico e Pedagógico "Voluntários da Pátria" e pelo Museu da Imagem e do Som "Maestro José Tescari" (MIS).

As ações desenvolvidas pelos profissionais envolvidos neste trabalho foram direcionadas para a realização de um diagnóstico do estado de conservação dos acervos musealizados; estudos e tratamentos técnicos adequados ao manuseio e acondicionamento de acervos; conservação de acervos históricos e arqueológicos; recuperação e restauro de acervos arqueológicos, inventários das coleções e, por fím, a educação patrimonial com dois públicos distintos: os Educandos da Escola Municipal Henrique Scabello e o COMCEDIR (Conselho Municipal de Combate à Discriminação e ao Racismo). 


\section{educação patrimonial e os espaços museais de araraquara-sp}

Atualmente, Araraquara conta com uma estrutura museal diversificada e que abriga diversas coleções de referência do patrimônio histórico e cultural regional. Ao todo são cinco museus, a saber: Museu de Arqueologia e Paleontologia de Araraquara (MAPA), Museu Histórico e Pedagógico "Voluntários da Pátria", Museu do Futebol, Museu Ferroviário e Museu da Imagem e do Som "Maestro José Tescari" (MIS), além do Arquivo Público "Prof. Rodolpho Telarolli" e do Centro de Conservação e Restauração de Acervos Diversos (CECRAD).

museu enquanto instituição é a base necessária à atividade museológica. Um espaço onde se aglutinam os processos do trabalho humano e seu contexto, isto é, "os testemunhos do Homem e do seu meio, seja do meio físico (natural), seja do meio transformado pelo Homem". Sua história está diretamente ligada ao desenvolvimento das organizações sociais da humanidade, relacionando-se aos diversos momentos de mudança, sejam estas econômicas, sociais, políticas ou culturais. Em sua formatação inicial, a partir do século XVIII, os primeiros museus, principalmente os europeus, foram criados no contexto da ideia do colecionismo, "que tentavam reviver o mundo greco-romano, evidenciava a grande estupefação da Europa com o Novo Mundo e o Oriente e incentivava as produções artísticas e científicas".

A coleção, eclética em sua origem, e baseada na valorização dos elementos culturais percebidos pelas elites e preservados para a perpetuação, por sua vez, demonstra sempre aspectos ligados aos seres humanos è à sua própria sociedade.

O colecionismo e a formação de museus, nesta perspectiva, influenciaram e ainda influenciam usuários profíssionais, bem como as ideias que se tem sobre as instituições museológicas e seus processos de musealização. Ao longo dos últimos anos e principalmente a partir dos anos 80 do século XX, observa-se que os museus assumiram diferentes papéis. Alguns museus incorporaram, a partir de novas reflexões sobre a utilidade social da ciência, "atitudes com relação ao entorno social, a ligação com múltiplos públicos e a responsabilidade social quanto ao retorno do desenvolvimento das pesquisas ${ }^{3 "}$.

${ }^{1}$ RUSSIO, Waldisa. Conceito de cultura e sua inter-relação com o patrimônio cultural e a preservação. IBPC, n. ${ }^{\circ}$ 3, São Paulo, 1990, p. 17).

${ }^{2}$ BRUNO, M. C. O. A Pesquisa em museologia: o programa técnico-científico do museu de Arqueologia e Etnologia da USP. In: Ciências em Museus, 3, SP, 1991.

${ }^{3}$ TAMANINI, Elizabete. O museu, a Arqueologia e o público: um olhar necessário. In: FUNARI, Pedro P. (org). Cultura material e arqueologia histórica. Coleção ideias 1. Unicamp. Campinas. 1999, p. 188.

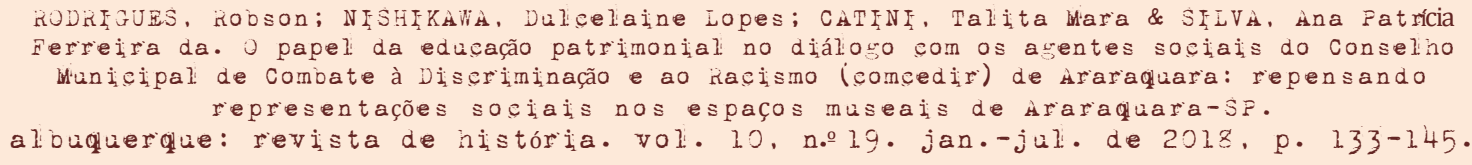


$\mathrm{Na}$ atualidade, a museologia tem alterado consideravelmente seu quadro conceitual, já que novos paradigmas vêm apoiando a ideia de musealização patrimonial, além do surgimento de novos modelos de museus. Hoje, convive-se com dois tipos distintos de modelos museológicos. Num dos conjuntos se encontram os modelos tradicionais apoiados em coleções que contam com edifício, quadro estável de pesquisadores e desenvolvem processos curatoriais, chegando à comunicação museológica por meio das exposições e projetos pedagógicos. São instituições que têm nas mãos as decisões sobre os seus programas de trabalho e cumprem um grande papel nas sociedades em que se inserem.

Em outro conjunto somam-se as experiências museológicas apoiadas no conceito de patrimônio integral, como os museus comunitários e ecomuseus. "São processos de tratamento patrimonial que partem da ideia de território, de uma comunidade vivendo neste território, construindo seu patrimônio e vivenciando o já existente e, sobretudo, decidindo sobre os critérios de musealização e preservação ${ }^{4 "}$

No processo de musealização, a dinâmica presente na sistemática do planejamento institucional, nas pesquisas prévias para a seleção dos objetos, no gerenciamento da informação que se dá na documentação e na conservação, entre outros elementos traduzidos no fato museal, para Bruno 5 , podem ser entendidos como um sistema de comunicação e apreensão de ideias, que direciona a ação da exposição do objeto em um cenário (museu). Nesse aspecto, cabe à museologia "medir os graus (intensidade) de emoção e conhecimento despertados no público pelo(s) objeto(s) exposto(s), a partir da experimentação de um tema (processo de musealização)", podendo, portanto, contribuir para o ensino e para a construção de uma imagem mais adequada sobre o patrimônio cultural.

A aplicação de ações educativas e definidas como Educação Patrimonial no âmbito do projeto Recuperação e Conservação de Acervos do Patrimônio Histórico e Cultural de Araraquara permitiu que pudessem ter clareza de que para se alcançar uma visão do passado no sentido de preservar e promover a sustentabilidade do patrimônio cultural local e regional era preciso estimular a imaginação do público acerca das outras épocas e outras formas de pensar os patrimônios existentes nos espaços museais.

${ }^{4}$ BRUNO, M.C. O. A pré-história nos museus: uma contribuição à educação. In: TENÓRIO, Maria Cristina, FRANCO, Teresa Cristina (Orgs.). Seminário para implantação da temática Pré-História Brasileira no ensino de $1^{\circ}, 2^{\circ}$ e $3^{\circ}$ Graus. Rio de Janeiro: UFRJ: Museu Nacional, 1994, p. 12.

${ }^{5}$ BRUNO, M. C. O. Arqueologia e museu: por quê? Para quem? Terra Indígena, Araraquara, v. 9, n 65, p. 37-43, 1992.

6lbidem, p. 10.

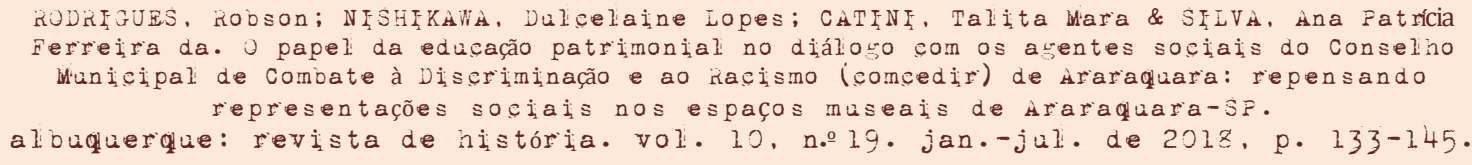


Essa perspectiva de ação pressupõe novos métodos didáticos de aprendizado, como a utilização de formas ativas que colocam o público no centro da ação pedagógica. Ao considerarmos o público como peça-chave de nossa ação, podemos vislumbrar de fato uma construção progressiva e durável do sentimento de pertencimento e valorização do patrimônio cultural.

Utilizamos o patrimônio arqueológico e histórico-cultural musealizado no município de Araraquara, com o intuito de atingir tais objetivos, pois entendemos que a sociedade precisa se apropriar desses bens culturais e se envolver com os conhecimentos produzidos a partir de estudos realizados com esse patrimônio.

Ao pensarmos esses conteúdos educativos de forma adequada e realizarmos a aplicação com grupos sociais, percebemos a possibilidade de reconhecimento, por parte destes, do valor cultural existente nesse patrimônio, permitindo possibilididades de identificação e, consequentemente, geração de desdobramentos preservacionistas.

Para promovermos a construção dessa identidade com o patrimônio histórico-cultural, utilizamos como eixo auxiliar a apresentação temática sobre a diversidade étnica e composição cultural de nossa sociedade, pois este processo estimula o conhecimento e rompe com os preconceitos, passando a gerar uma relação respeitosa no que compete às diferenças existentes no nosso entorno, sejam elas étnicas, sociais ou de gênero.

Ao respeitar essa diversidade e estimular de maneira lúdica e participativa o entendimento do patrimônio histórico e cultural, nos deparamos com um conjunto de informações geradas por meio da relação educador e educando.

Ao desenvolvermos as ações educativas, no âmbito do projeto em questão, tivemos como principal finalidade aproximar os grupos sociais e as escolas, dos museus de Araraquara, pois entendemos que esses grupos têm uma importância social para a preservação dos patrimônios culturais musealizados.

Em nossa concepção, os espaços museais devem ser ocupados pela sociedade como um todo. Diante desse desafío, passamos a construir essa ideia conjuntamente com grupos previamente identificados, no sentido de desenvolver uma ação piloto e que futuramente venha a ser replicada.

Para tanto, iniciamos um diálogo com o grupo de educadores, educandos e sociedade civil, passando a incorporar os diversos saberes desses segmentos sociais na medida em que foram sendo desenvolvidas as oficinas educativas. A ideia-chave se deu a partir do reconhecimento de que patrimônios culturais existentes nos museus podem e devem significar um espaço da construção da nossa própría

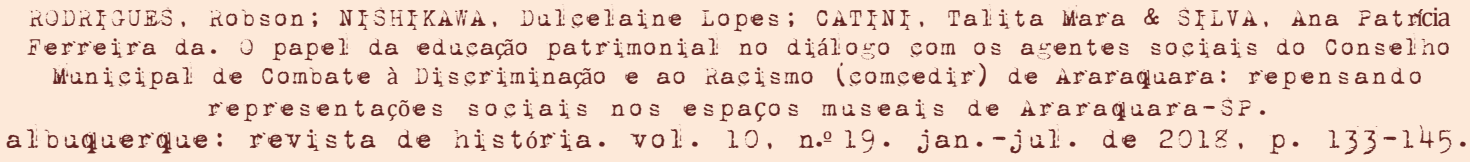


história. Nesse processo, a intenção foì registrar a percepção que as comunidades envolvidas têm do patrimônio cultural, bem como entender qual é a concepção de seus membros sobre os patrimônios que se encontram nos espaços museais.

A nossa proposta pedagógica se aproxima das formulações filosóficas de Paulo Freire. Este autor defende a ideia de que a educação está associada a uma forma de ler o mundo. E nesse mundo todos os sujeitos produzem conhecimento e, portanto, geram cultura. Sendo assim, a educação não é a mera reprodução do conhecimento. Para Freire a educação é um ato político?

Na concepção Freiriana que adotamos não se deve fazer uma política cultural sem se conceber como estratégíco o envolvimento de todos os sujeitos. $\bigcirc$ conceito de educação popular consiste em um "esforço de mobilização, organização e capacitação dos sujeitos"8 e acreditamos que esse também deva ser o papel do educador que trabalha com patrimônio cultural. $\mathrm{Na}$ compreensão de Freire era preciso ler o mundo para poder transformá-lo ${ }^{9}$ Por esta razão sua teoria passa por uma visão crítica e não pela mera reprodução técnica. Perpassa pela ideia de que é preciso valorizar o conhecimento dos sujeitos, assim como a sua produção cultural. Essa valorização possíbilitará uma relação de pertencimento e identidade com os bens patrimoniais e culturais e a consciência de seus direitos, como sua inserção crítica na realidade.

À medida que os sujeitos vão se organizando, estes produzem uma forma cada vez mais racional de pensar que se dá por meio da problematização de seu mundo e da análise crítica de sua prática. Essa sistemática permitirá uma atuação cada vez mais segura e interventiva no mundo, visando novas construções socioculturais.

A nossa opção por trabalhar com comunidades escolares e grupos sociais, possibilitando não apenas o conhecimento científico, mas ampliando a visão do patrimônio material e imaterial como sendo uma forma de todos os atores sociais estarem representados, proporciona um movimento de sensibilização. Entendemos que retirar o direito desses grupos sociais de conhecer e vivenciar os patrimônios culturais é promover um processo de exclusão social.

Na dinâmica da Educação Patrimonial, muitas fontes são utilizadas, dentre as quais podemos citar a utilização de dados etnográficos, iconográficos, históricos,

\footnotetext{
${ }^{7}$ FREIRE, Paulo. Pedagogia do oprimido. 17ª ed. Rio de Janeiro: Paz e Terra, 1987. 8 Idem.

9 GADOTTI, Moacir. Los aportes de Paulo Freire a la pedagogía crítica. Revista Educacíon, 2002, n.26, vol.2.
} 
a partir do elemento documental e oral, bem como a cultura material. Nesse processo, Funari comenta que:

Precisamos ter claro que tanto os documentos escritos quanto a cultura material são produtos de uma mesma sociedade, mas não necessariamente complementares ou convergentes, pois o documento escrito representa as ideias ou interesses subjetivos de seu autor, o que diferencia da cultura material. (...) os documentos escritos informam-nos sobre as ideias de seus autores, em geral, pertencentes a uma minoria dos que sabem escrever. A escrita, assim, é um instrumento de poder de classe. ${ }^{10}$

No entanto, a cultura material aproxima a sociedade como um todo, pois ela é o reflexo da construção coletiva de forma naturalizada sem a preocupação de ter um caráter erudito ou formal.

A cultura material, por outro lado, é o resultado, em grande parte, de esforços das pessoas comuns e conserva-se, muitas vezes, sem que assim se queira ou planeje, como testemunhos involuntários da história11.

Assim, a nossa perspectiva é a busca de uma abordagem inclusiva, ou seja, um movimento do fomento da autoestima nas comunidades locais por meio do conhecimento, estimulando e valorizando o patrimônio cultural local, a memória e as identidades culturais. A procura é pela sensibilização das comunidades no sentido de se promover a preservação das variadas formas de patrimônio material e imaterial, pois esses são suportes da memória e identidade cultural12.

Enquanto grupo, nosso intuito é gerar o empoderamento dos diversos segmentos da sociedade, a partir do reconhecimento de pertencimento desses patrimônios. $\bigcirc$ que se procura é romper com a visão hegemônica de grupos dominadores do passado, em favor de uma visão plural, que permita a percepção da rica diversidade sociocultural, tanto na sociedade do passado quanto na do presente.

10 FUNARI, P.P. Arqueologia. São Paulo, Contexto, 2003, p. 40.

11 Idem.

${ }^{12}$ CERQUEIRA, Fábio V.; ZORZI, Mariciana; MACIEL, Luísa M.; SCHUWANZ, Jezuína K. Considerações conceituais e metodológicas sobre projetos de educação patrimonial. Revista de Arqueologia Pública. Campinas-SP n04, 2011.

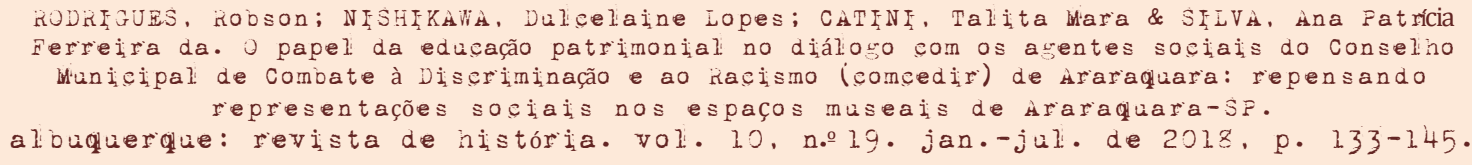


Nesta perspectiva, patrimônio não é mais visto como sinônimo de erudito, da genialidade, algo distante dos demais membros da sociedade. É possível compreender a diversidade cultural existente e que perpassa tanto pela cultura erudita ou monumental, quanto pela popular

Entendemos que precisamos desconstruír a visão de que os espaços museais, bem como o patrimônio cultural, representam apenas um segmento de nossa sociedade. Em nossa concepção, os espaços culturais e seu patrimônio pertencem a todos

Para se promover um processo de sensibilização e valorização do patrimônio cultural local, salientamos que o olhar e a construção devem ser interdisciplinares. Ao envolvermos profissionais das áreas de História. Arqueologia, Sociologia, Antropología, Conservação e Restauro, dentre outros, poderemos desenvolver estudos e pareceres técnicos para contríbuir com a construção de políticas públicas que valorizem o patrimônio cultural e desenvolvam processos de conservação e preservação mais adequados

Em conjunto com um trabalho de educação que envolve os grupos sociais diversos, formamos multiplicadores que efetivamente poderão difundir o reconhecimento e valorização desses patrimônios musealizados.

Compreendemos, assim como Cerqueira ${ }^{13}$ que as ações educativas podem primeiramente potencializar a sociedade tirando a exclusividade de pensar o patrimônio local do profissional da museologia ou de restauro. Pode-se capacitar os cidadãos para serem cooperadores e físcalizadores da conservação dos patrimônios culturais e, também, levá-los a participar da atuação política, principalmente nas ações decisórias a respeito de quais bens devem ser patrimonializados podendo, inclusive, incluí-los em ações públicas ou participação em financiamentos para a promoção da conservação, restauro e sustentabilidade dos patrimônios culturaís.

Nesse sentido, as ações educativas, em Araraquara, tiveram por objetivo sensibilizar e tornar a sociedade araraquarense parceira do projeto cultural e educacional no contexto dos museus e instituições participantes. A finalidade era criar uma relação com as instituições e as demais parcerias que surgiram no percurso do projeto e promover a compreensão da importâncía da apropriação desses espaços enquanto local para construção da cultura local. Além de se iniciar um processo de sensibilização para a necessidade de cuidado e de preservação do acervo cultural já musealizado no município.

${ }^{13}$ CERQUEIRA, Fábio V. Educação Patrimonial na Escola. Por que e Como? In.: CERQUEIRA, V. Fabio; GUTIERREZ, Ester Judite Bendouya; SANTOS, Denise Ondina Marroni dos; MELO Alan Dutra de (org.) Educação Patrimonial: perspectivas Multidisciplinares. Pelotas, Instituto de Memória e Patrimônio, 2008.

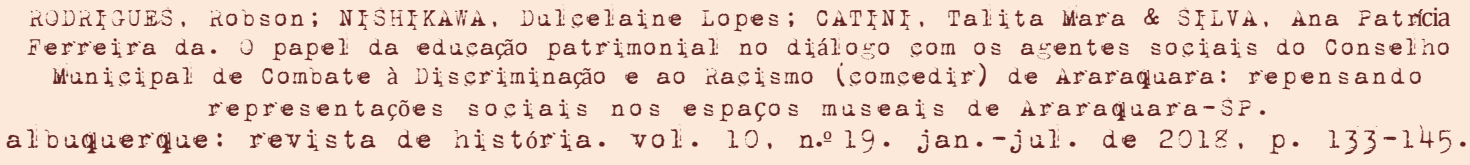




\title{
a escolha dos grupos sociais
}

A Escola Municipal de Ensino Fundamental "Professor Henrique Scabello" está instalada no Jardim das Hortênsias, região periférica do município de Araraquara e foi escolhida pelo fato de as crianças participarem do Programa de Educação Complementar (PEC), implantado nessa escola.

A escolha por se trabalhar com o Programa de Educação Complementar se deu também pela dificuldade em se propor ações continuadas dentro da grade curricular do ensino fundamental e médio de escolas no município após o início do ano letivo. Como bem define Cerqueira e outros, entendemos que,

\begin{abstract}
A escola, em decorrência da constatação da importância social da educação patrimonial, foi colocada diante de um impasse: ao chamar para si a responsabilídade pela promoção da educação patrimonial entre jovens e crianças, constatou a dificuldade de inserir em seu cotidiano a educação patrimonial, que deve ser necessariamente multidisciplinar e indispensavelmente participativa - precisa não somente introduzir entre os educandos conceitos e informações técnicas, mas, sobretudo, semear a sensibilidade para o patrimônio cultural, para que, em futuro próximo, possamos colher os frutos de uma sociedade mais comprometida com a valorização de seu patrimônio, de sua memória e de sua identidade ${ }^{14}$.
\end{abstract}

É evidente a necessidade de se promover a educação patrimonial entre jovens e crianças, mas a formalização institucional cria entraves a isso na medida em que a grade curricular não abre espaço para ações multidisciplinares essenciais a uma boa problematização da importância do patrimônio cultural. Nesse contexto, a educação patrimonial tem que ser mais abrangente do que o conhecimento meramente técnico, sendo necessário um diálogo multidisciplinar, transversal, para que se possa, de fato, sensibilizar os indivíduos a respeito do patrimônio cultural.

Diante dessa constatação, decidiu-se pelo desenvolvimento da proposta educativa junto à EMEF Prof. Henrique Scabello, em conjunto com o Programa de Educação Complementar, pois nesse contexto, observaram-se boas condições de atuação de maneira contínua não interferindo na dinâmica curricular da unidade escolar.

${ }^{14}$ CERQUEIRA, Fábio V., ZORZI, Mariciana, MACIEL, Luísa M. e SCHUWANZ, Jezuína K. Considerações conceituais e metodológicas sobre projetos de educação patrimonial. Revista de Arqueologia Pública. Campinas, $n^{\circ} 4,2011$, p. 22.

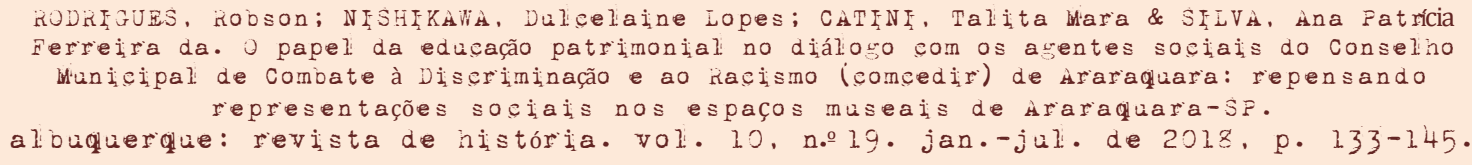


O Programa de Educação Complementar é destinado a alunos de cinco anos e meio a catorze anos de idade, que estudam no ensino regular em outro período. A matrícula dos alunos nas unidades de Educação Complementar só é garantida mediante a comprovação de sua frequência no ensino regular. $\bigcirc$ objetivo desse Programa é justamente o de complementar a educação regular por meio de atividades pedagógicas direcionadas às diferentes linguagens culturaís e à percepção sobre cidadania. De acordo com a definição de Capaldo, o Programa de Educação Complementar tem como preocupação:

1) Respeitar cada criança e cada adolescente como pessoa humana em processo de desenvolvimento, resguardando sua imagem e identidade, sua autonomia, seu espaço e objetos pessoais, garantindo-lhes integridade física e psíquica; 2) Levar o aluno a agir com autonomia nas decisões pessoais e nas relações sociais, valorizando as contribuições próprias e alheias e respeitando os princípios básicos de uma sociedade democrática; 3) Reconhecer no patrimônio cultural a diversidade linguística e artística como direito dos povos e dos indivíduos, desenvolvendo interesse, respeito e tolerância; 4) Apreender os modos corretos de representação da linguagem, construindo e interpretando coerentemente textos diversos, utilizando-os como instrumentos de comunicação, de reivindicação e de inserção no mundo social; 5) Interessar-se pelo trabalho em equipe, valorizando os comportamentos cooperativo, solidário e responsável, e demonstrando conhecimento, flexibilidade, idoneidade, criatividade, estabilidade emocional e confiança; 6) Por último, é também objetivo da Educação Complementar educar para o reconhecimento da relação entre o social e o natural nas questões ambientais, tendo em conta a participação e a articulação como poder público na busca de soluções para problemas que afetam a sociedade ${ }^{15}$.

Propusemos que as ações fossem executadas no Programa de Educação Complementar devido ao mesmo comungar com os objetivos do projeto de Recuperação e Conservação de Acervos do Patrimônio Histórico e Cultural de Araraquara, pois em nossa proposta buscamos compreender aspectos históricos, culturais, arqueológicos e museais de Araraquara de forma diretamente inseridos na sociedade local, assim pudemos desenvolver as ações educativas de modo continuado e sem, contudo, interferir na grade curricular escolar.

${ }^{15}$ CAPALDO, O. L. Educação complementar: um projeto político-pedagógico. Araraquara, 2006 (não publicado).

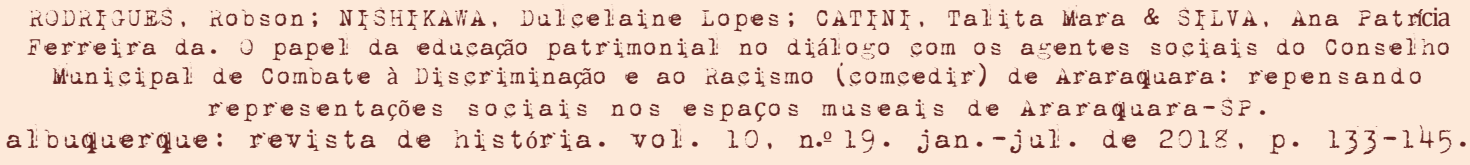


A escolha pelo COMCEDIR se deu pelo fato de o conselho estar vinculado à Secretaria Municipal de Articulação Institucional e Participação Popular. O conselho tem como responsabilidade elaborar e programar, em todos os domínios da administração do município, políticas públicas sob a ótica racial, para garantír a igualdade de oportunidades e de direitos das diversas etnias. A lei que regulamentou a existência do conselho foi formulada em outubro de 2013. O COMCEDIR é um órgão consultivo e deliberativo, de participação direta da comunidade, do poder público municipal e de entidades representativas dos movimentos sociais. Dentre suas competências está o desenvolvimento de ações conjuntas com outras secretarias e demais grupos que estejam fomentando ações que busquem romper com o preconceito e desigualdade raciais. $\bigcirc$ conselho também promove estudos e 0 debate sobre as condições em que vive a população afrodescendente na cidade e no campo, propondo políticas que promovam a total eliminação de processo discriminatórios.

Ao propormos ações de reconhecimento e pertencimento entre os conselheiros e os museus estimulamos o desenvolvimento de pesquisas e estudos sobre a produção da população afrodescendente. As atividades também contribuíram para a construção de uma reflexão sobre os acervos e processos de inserção da população afrodescendente na cultura de Araraquara.

Como o principal pressuposto relacionado à Educação Patrimonial é o de promover a igualdade racial, o respeito à diversidade e a sensibilização para os diversos bens patrimoniais das diferentes culturas, justificou-se plenamente nossa ação conjunta com o Conselho Municipal de Combate à Discriminação e ao Racismo de Araraquara.

No âmbito da execução das atividades de Educação Patrimonial foram desenvolvidas quatro oficinas temáticas, a saber: sociomuseologia; Arqueólogo por um dia; Cerâmica indígena - técnica do acordelado e Isogravura - Diversidade Etnica e Representação Gráfica.

A oficina de sociomuseologia foi desenvolvida no ambiente do Museu Histórico e Pedagógico "Voluntários da Pátria", tendo como principais assuntos discutidos noções de como se deu a constituição histórica dos museus e a quem representavam estas instituições. No decorrer do desenvolvimento também foram apresentados referenciais conceituais da nova museologia e da sociomuseologia. Como atividade prática e após a explanação mais conceitual, partiu-se para uma exploração do ambiente museal em que os participantes se encontravam.

A oficina "Arqueólogo por um dia" foi desenvolvido no ambiente do MAPA - Museu de Arqueologia e Paleontologia de Araraquara.

\footnotetext{
RODKFGUES, kobson; NFSHFKHA, Dulcelaine Lopes; ChTFN, Talita Mara \& SFLVA, Hna Fatrícia Ferreira da. O papel da educaça patrimonial no diálošo com os a tentes sociais do Conselino unicipal de Combate à Discriminaça e ao kacismo (comeedir) de sraraquara: repensando representações sociais nos espaços museais de Araraquara-sf. albuquerque: revista de história. val. 10, no 19. jan.-jul. de 2018. p. 133-145.
} 
Nesta oficina desenvolvemos ideias a respeito dos processos de musealização da Arqueologia, bem como noções sobre qual a importância dos acervos arqueológicos, ou seja, da cultura material, para a compreensão das representações dos sujeitos e das construções sociais.

Entendemos que grande parte da população brasileira desconhece a riqueza e a diversidade do patrimônio arqueológico nacional. Por essa razão, percebemos a dificuldade que os cidadãos têm em se identificar e estabelecer uma relação de proximidade entre patrimônio arqueológico e comunidade. Esse fato ocorre porque, como bem define Bezerra ${ }^{16}$, a Arqueologia no Brasil quando associada à educação é entendida como algo complementar, que acrescenta ao indivíduo informações interessantes, mas que não está intimamente ligada à históría e identidade da sociedade nacional. Esta dificuldade pode ser explicada, primeiramente, pelo mito fundador do Brasil e pela criação de uma história brasileira que começa com a colonização, negando aos povos indígenas a posição de atores sociais ${ }^{17}$.

não reconhecimento do público brasileiro para com a realidade dos povos indígenas dificulta o diálogo com a Arqueologia brasileira, sobretudo no que diz respeito aos objetos associados às ocupações dos povos pré-cabralinos, um elemento exótico ao olhar da maioria dos brasileiros. Segundo Chaui1 ${ }^{18}$ e Bezerra ${ }^{19}$, a criação de um "mito fundador", a partir da ideia de nação, distancia o povo brasileiro de sua diversidade cultural e étnica, aproximando-o cada vez mais do legado deixado pelo colonizador.

E para avançarmos nas discussões a respeito da diversidade étnica e indígena com a sociedade envolvente, dentre nossas ações, é que desenvolvemos as ofícinas "Cerâmica indígena: técnica do acordelado e Isogravura: diversidade étnica e representação gráfica", com as quais apresentamos conceitos e conhecimentos a respeito das populações indígenas ${ }^{20}$ brasileiras tendo em vista criarmos possibilidades de ruptura de paradigmas equivocados e preconceituosos.

16 BEZERRA, M, de A, 2002. O australopiteco corcunda. As crianças e a Arqueologia em um Projeto de Arqueologia Pública na Escola. Tese de doutorado em Arqueologia. Faculdade de Filosofia, Letras e ciências humanas, Universidade de São Paulo, SP, 2002.

17 CHAUÍ, Marilena. Brasil: Mito Fundador e Sociedade Autoritária. São Paulo: Ed. Perseu Abramo, 2000.

18 Idem.

19 BEZERRA, M. de A. op. cit.

20 VIDAL, Lux e LOPES DA SILVA, Aracy. Antropologia estética: enfoques teóricos e contribuições metodológicas. IN: VIDAL, Lux (org.). Grafismo Indígena: estudos de antropologia estética. São Paulo: Studio Nobel: Editora da Universidade de São Paulo: FAPESP, 1992.

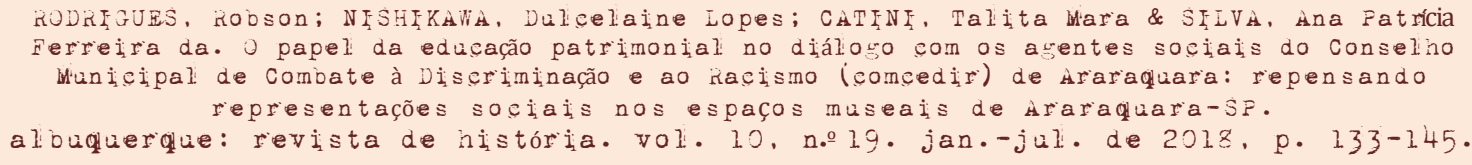




\section{considerações finais}

Ao finalizar essa reflexão precisamos apontar que é necessário desconstruir a visão de que os espaços museais, bem como o patrimônio cultural, representa apenas um segmento de nossa sociedade. Na nossa concepção, os espaços culturais e seu patrimônio pertencem a todos. Por acreditarmos nessa perspectiva, sempre buscamos uma abordagem inclusiva, ou seja, um movimento do fomento da autoestima nas comunidades locais por meio do conhecimento, estimulando e valorizando o patrimônio cultural local, a memória e as identidades culturais. No entanto, reconhecemos que temos um longo caminho a ser seguido para atingir esse objetivo.

Ao desenvolvermos os nossos trabalhos nos deparamos ainda com a presença de um pensamento preconceituoso a respeito da condição cultural e econômica dos educandos. E o mais triste é que os próprios educadores tratam as crianças de forma preconceituosa devido aos mesmos habitarem um bairro periférico, com altos índices de violência e terem uma baixa renda econômica.

que evidencia a necessidade contínua de criar condições para tornar os ambientes dos museus mais acessíveis aos diversos grupos sociais. Em nossa concepção a Educação Patrimonial deve ser essa ferramenta para estimular o conhecimento e a valorização dos testemunhos culturais e indenitários das comunidades locais e também, deve fortalecer e construir o sentimento de tolerância à diversidade cultural. Acima de tudo, deve estimular a sensibilidade dos sujeitos para que possam admirar a cultura dos outros povos, de outras regiões e outras épocas, cujos registros culturais expressam a riqueza da cultura humana como bem definido na Declaração da UNESCO sobre a Diversidade Cultural ${ }^{21}$

21 UNESCO. DECLARAÇÃO UNIVERSAL DA UNESCO SOBRE A DIVERSIDADE CULTURAL. 2002. Disponível em : < http://unesdoc.unesco.org/images/0012/001271/127160por.pdf>. Acesso 20 jan. 2017.

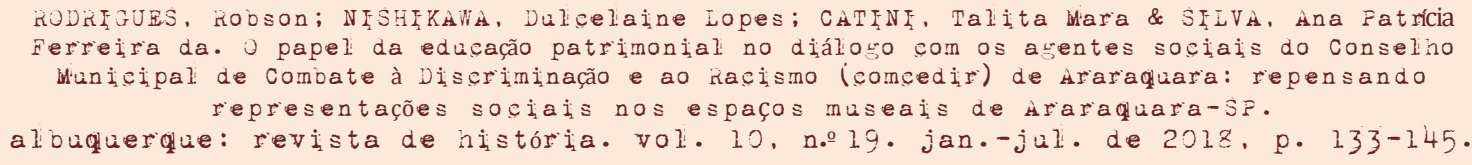

